\title{
The Analysis on Fat Characteristics of Walnut Varieties in Different Production Areas of Shanxi Province
}

\author{
Chang Yuemei ${ }^{1}$, Du Junmin ${ }^{2} \&$ Zhang Caihong ${ }^{1}$ \\ ${ }^{1}$ Shanxi Academy of Forestry Sciences, Taiyuan, P. R. China \\ ${ }^{2}$ Department of Traditional Chinese Pharmacology, Shanxi University of Traditional Chinese Medicine, Taiyuan, \\ P. R. China \\ Correspondence: Du Junmin, Department of Traditional Chinese Pharmacology, Shanxi University of Traditional \\ Chinese Medicine, Taiyuan, P. R. China. Tel: 86-351-408-4708. E-mail: dujmtcm@163.com
}

Received: July 22, 2013 Accepted: October 6, 2013 Online Published: October 12, 2013

doi:10.5539/jps.v3n1p28 URL: http://dx.doi.org/10.5539/jps.v3n1p28

\begin{abstract}
To gain knowledge of the fat characteristics of walnut varieties in different production areas of Shanxi Province, kernel oil content and its fatty acid composition of 6 walnut varieties were analyzed by using soxhlet extraction method and gas chromatography. The experiment sites were Yicheng and Tunliu. Yicheng has $800 \mathrm{~m}$ of altitude and $11{ }^{\circ} \mathrm{C}$ of annual mean temperature while Tunliu has $1100 \mathrm{~m}$ of altitude and $9.3{ }^{\circ} \mathrm{C}$ of annual mean temperature. The results indicated between Yicheng and Tunliu County, the most variety's oil content was increased with increasing of altitude, but had no significant difference $(64.9 \%>64.3 \%, \mathrm{P}>0.05)$. Both the content of oleic acid and linoleic acid showed a significant difference between Tunliu and Yicheng, and there is a negative relationship between the contents of oleic and linoleic acid. Annual mean temperature has an obvious influence on $\alpha$-linolenic acid (ALA) content of walnut. The content of ALA from Yicheng with higher annual mean temperature is higher than that from Tunliu with lower annual mean temperature. The nutrition analysis showed that Tunliu' walnut kernel has a lower saturated fatty acids (SFA) $(7.6 \%<8.2 \%, \mathrm{P}<0.05)$ and a higher unsaturated fatty acids (UFA) $(92.5 \%>91.8 \%, \mathrm{P}<0.05)$ compared to Yicheng, respectively, but the polyunsaturated fatty acids (PUFA) content of Yicheng was higher than that of Tunliu $(76.3 \%>68.5 \%, \mathrm{P}<0.05)$, and its ratio of N-6/N-3 was also better compared to Tunliu $(5.4: 1<5.9: 1)$. These results showed that with the different altitude and annual mean temperature, the walnut nutrition of fat is also different. Higher altitude and lower annual mean temperature can help to produce oleic-rich walnut while lower altitude and higher annual mean temperature is helpful for the higher content of ALA in walnut kernel.
\end{abstract}

Keywords: production area, walnut, fatty acid, nutrition

\section{Introduction}

Walnut kernel contains around 60-70\% of oil, and can be praised as "the oil store on the tree" (Li et al., 2009). Walnut is a rich source of energy for life. People prefer plant oils to animal fat due to concerning about animal cholesterol (Pyorala, 1987). Plant oils don't contain any animal cholesterol; but it contains a large amount of unsaturated fatty acids (UFA) that benefit human health. The UFA content of walnut oil is more than $90 \%$.

To obtain the perfect nutrition characteristics of fatty acid composition of walnut, a lot of investigations have been done about variety (Wang et al., 2004; Chen et al., 2007; Wu et al., 2007). However, the results are not quite consistent even the same cultivars. It is reported that the external site conditions including altitude, air temperature, average annual relative humidity, longitude, may affect the single fruit kernel weight, accumulation of saturated fatty acid (SFA), monounsaturated fatty acid (MUFA) and polyunsaturated fatty acid (PUFA) during the plant growing season (Zhang et al., 2011; Li Guo et al., 2007; Xu et al., 2009). In order to gain knowledge of the fat characteristics of walnut in different production areas, the effect of production area on walnut oil quality is necessary to be investigated. Shanxi belongs to mountainous region which develops different climate conditions. Moreover, its total plant area of walnut is also large (Cheng, 2011), so we selected Shanxi as experimental site to determine the effect of producing region of walnut on oil quality. 


\section{Experimental}

\subsection{Materials}

Walnut samples were collected at Yicheng County and Tunliu County, in Shanxi province of China during 8-9, 2012. The condition data of the two sites were shown in Table 1.The cultivars included Liaoning No. 1, Luguang, Lipin No. 2, Beijing 861, Zhonglin No. 1 and Zhonglin No. 3.

Table 1. Some climate and soil characteristic in walnut producing regions

\begin{tabular}{llllll}
\hline Producing regions & Altitude $/ \mathrm{m}$ & Annual mean temperature $/{ }^{\circ} \mathrm{C}$ & $\begin{array}{l}\text { Yearly precipitation } \\
/ \mathrm{mm}\end{array}$ & $\begin{array}{l}\text { Frost-free } \\
\text { Period } / \mathrm{d}\end{array}$ & $\begin{array}{l}\mathrm{pH} \text { value } \\
\text { of soil }\end{array}$ \\
\hline Tunliu & 1200 & 9.3 & 560 & 157 & 8.2 \\
Yicheng & 800 & 11.0 & 550 & 190 & 7.2 \\
\hline
\end{tabular}

\subsection{Analysis of Oil Content}

Oil content of walnut was determined by GB/T5009.6-2003 first method "Soxhlet extraction method". According to the method 3-5 g of walnut kernel powder was weighted, wrapped with filter paper and laid in Soxhlet extractor. A $50-60 \mathrm{ml}$ solvent of petroleum ether $\left(60-90{ }^{\circ} \mathrm{C}\right)$ was added and refluxed for $8 \mathrm{~h}$. The oil content of walnut kernel was determined gravimetrically after complete evaporation of solvent to the dryness at $45^{\circ} \mathrm{C}$ using a rotary evaporator.

\subsection{Analysis of Fatty Acids by Gas Chromatography}

20-30mg of walnut oil was weighted and esterified through sodium methoxide. Fatty acid methyl esters were analyzed on a Lufen company gas chromatograph GC6500 with flame-ionization detector. The glass column packed with $20 \%$ DEGS on Chromsorb (4 mm i.d. $\times 1.1 \mathrm{~m}$ length) was employed; N2 was used as a carrier gas; the column temperature was $190^{\circ} \mathrm{C}$ and the injector and detector temperatures were $250{ }^{\circ} \mathrm{C}$. The content of fatty acid was obtained by calculating the peak area percentage method. Figure 1 is the typical fatty acid chromatography of Liaoning No.1 walnut oil from Tunliu County.

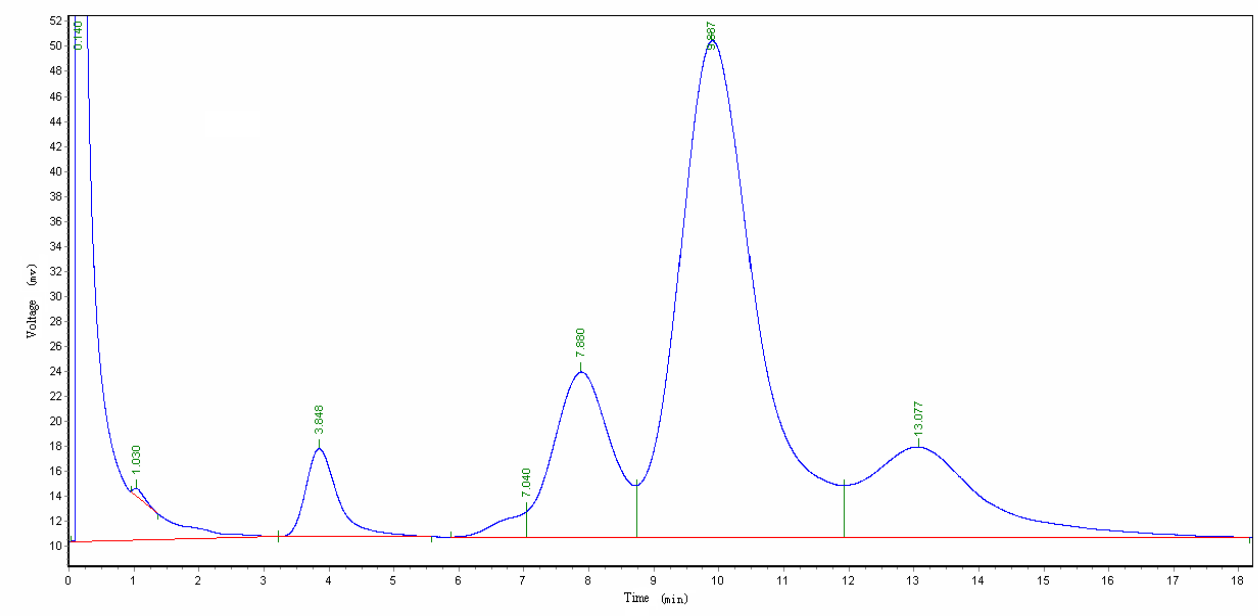

Figure1. The typical fatty acid chromatography of Liaoning No.1 walnut oil from Tunliu County

3.848min: Palmitic acid $\left(\mathrm{C}_{16: 0}\right), 4.040 \mathrm{~min}$ : Stearic acid $\left(\mathrm{C}_{18: 0}\right), 7.880 \mathrm{~min}$ : Oleic acid $\left(\mathrm{C}_{18: 1}\right), 9.887$ min: linoleic acid $\left(\mathrm{C}_{18: 2}\right), 13.077$ min: $\alpha$-linolenic acid $\left(\mathrm{C}_{18: 3}\right)$. 


\section{Results and Discussion}

\subsection{Analysis of Oil Content and Fatty Acid Content of Walnut in Different Production Areas}

6 varieties of walnut were selected to inspect the effects of two different production areas (Tunliu and Yicheng) on walnut oil content and fatty acid content. Figure 2 showed that the oil content of the same varieties from Tunliu was more than that of Yicheng except Zhonglin series (No.1 and No.3), but the average value of Tunliu was a little higher than that of Yicheng $(64.9 \%>64.3 \%)$. The factors ( $\mathrm{Li}$ et al., 2010) influencing oil content includes genetic quality, seed maturity, and fruiting number, etc. In our study these factors were controlled to be as similar as possible. However, there are still some of differences of climatic conditions such as altitude and yearly precipitation. Altitude has a positive effect on walnut single fruit kernel weight and kernel percent (Zhang et al., 2011), but it can be considered with water factor as far as the oil content. Altitude of Tunliu is about $1100 \mathrm{~m}$ more than $800 \mathrm{~m}$ of Yicheng, and the yearly precipitation is also higher than that of Yicheng. During fruit development, the moisture of soil was higher in Tunliu of high altitude than that in Yicheng of lower altitude, and water help to the nutrition absorption for the synthesis of oil, which was seen in most of variety except for Zhonglin No.1 and Zhonglin No.3.

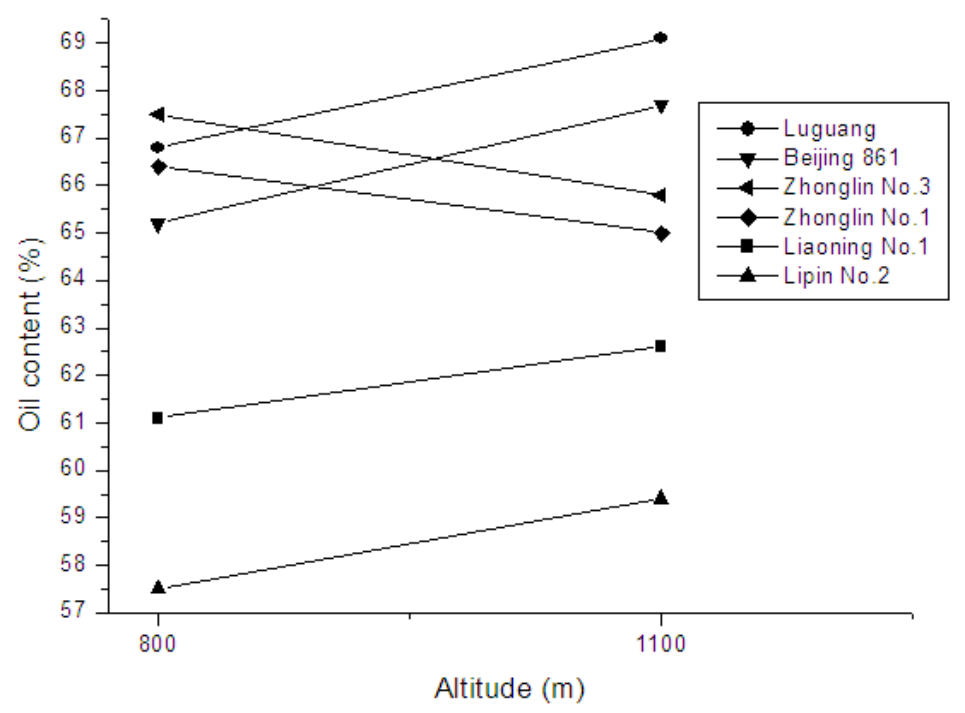

Figure 2. The oil content of walnut with increasing of altitude

Frost-free period means plant growth period, but even the frost-free period in Yicheng was approximate to one month longer than that in Tunliu, there was not obvious increment in oil content. This indicated that the synthesis of oil can be related with altitude and water rather than plant growth time. The $\mathrm{pH}$ value of soil can have different influences on oil content due to walnut variety. Zhonglin series including Zhonglin No.1 and Zhonglin No.3 were suitable in milder alkaline soil of Yicheng, while higher $\mathrm{pH}$ value of soil of Tunliu was more suitable for the most of varieties. Tree-oil crops preferred calcareous soils ( $\mathrm{Li}$ et al., 2010) where higher $\mathrm{pH}$ value of soil was usually seen. However, the content of oil of the most varieties from Tunliu was more than that from Yicheng. It was found that the climate played a more important effect on walnut compared to soil (Cao, 1994). From the view of climate, the oil content of higher altitude was more than that of lower altitude, but the difference was insignificant $(\mathrm{P}>0.05)$. This might be due to the little sample number.

From Tables 2-3, there was no difference in main composition kinds of fatty acid. But there was significant difference in oleic content, the major monounsaturated fatty acid (MUFA) in walnut; the average content from Tunliu was more than that from Yicheng as far as MUFA $(23.8 \%>15.0 \%, \mathrm{P}<0.05)$. On the contrary, linoleic acid content of Tunliu was less than that of Yicheng, $(58.4 \%<64.2 \%, \mathrm{P}<0.05)$. Higher altitude can produce the higher oleic acid content, especially with lower annual mean temperature. 
Table 2. The fatty acid composition of walnut kernel in Yicheng County (\%)

\begin{tabular}{lllllll}
\hline $\begin{array}{l}\text { Walnut } \\
\text { Varieties }\end{array}$ & $\mathrm{C}_{16: 0}$ & $\mathrm{C}_{18: 0}$ & $\mathrm{C}_{18: 1}$ & $\mathrm{C}_{18: 2}$ & $\mathrm{C}_{18: 3}$ & $\begin{array}{l}\text { Other } \\
\text { acids }\end{array}$ \\
\hline Liaoning No.1 & 6.1 & 1.8 & 20.7 & 58.4 & 13.1 & 0.1 \\
Luguang & 6.7 & 1.7 & 16.0 & 63.2 & 12.4 & 0.0 \\
Lipin No.2 & 6.7 & 1.5 & 15.2 & 65.8 & 10.8 & 0.1 \\
Beijing861 & 6.0 & 2.2 & 12.4 & 68.5 & 10.9 & 0.1 \\
Zhonglin No.1 & 6.6 & 2.3 & 14.2 & 65.7 & 11.2 & 0.0 \\
Zhonglin No.3 & 6.5 & 1.2 & 11.4 & 63.5 & 14.4 & 3.1 \\
Average & 6.4 & 1.8 & 15.0 & 64.2 & 12.1 & 0.6 \\
\hline
\end{tabular}

Table 3. The fatty acid composition of walnut kernel in Tunliu County (\%)

\begin{tabular}{lllllll}
\hline $\begin{array}{l}\text { Walnut } \\
\text { Varieties }\end{array}$ & $\mathrm{C}_{16: 0}$ & $\mathrm{C}_{18: 0}$ & $\mathrm{C}_{18: 1}$ & $\mathrm{C}_{18: 2}$ & $\mathrm{C}_{18: 3}$ & $\begin{array}{l}\text { Other } \\
\text { acids }\end{array}$ \\
\hline Liaoning No.1 & 6.7 & 1.9 & 13.3 & 66.5 & 11.5 & 0.1 \\
Luguang & 6.2 & 1.3 & 19.5 & 60.6 & 12.0 & 0.4 \\
Lipin No.2 & 5.1 & 1.8 & 31.4 & 54.5 & 7.2 & 0.0 \\
Beijing861 & 4.6 & 1.0 & 22.4 & 61.7 & 10.3 & 0.1 \\
Zhonglin No.1 & 6.3 & 2.2 & 33.1 & 48.1 & 10.5 & 0.0 \\
Zhonglin No.3 & 6.6 & 1.6 & 23.3 & 59.1 & 9.4 & 0.0 \\
Average & 5.9 & 1.6 & 23.8 & 58.4 & 10.2 & 0.3 \\
\hline
\end{tabular}

An extremely negative correlation is observed between the contents of oleic and linoleic acid in cameillia oleifera fruit trees (Wang et al., 2008) and this same relationship was also proved existed in walnut trees in our results. This phenomenon probably rises from the saturate conversion of the two fatty acids of same carbon chain length. Although the samples are from two different production areas, the content relationship between oleic acid and linoleic acid appears to be same. Therefore, the differences of oleic and linoleic acid from two production areas can be considered as one index of fatty acid to compare. Our results showed that Tunliu is suitable for MUFA-rich or oleic-rich walnut, in other words, Yicheng is suitable area for linoleic acid-rich walnut.

\subsection{Comparison of Nutrition Characteristics of Walnut From Two Production Areas}

The nutrition characteristics of walnut fatty acids was compared on Tables 4-5. Tunliu has a lower of SFA (7.6\% $<8.2 \%, \mathrm{P}<0.05)$ and a higher UFA $(92.5 \%>91.8 \%, \mathrm{P}<0.05)$ compared to Yicheng, respectively, but the polyunsaturated fatty acids (PUFA) content of Yicheng was higher than that of Tunliu $(76.3 \%>68.5 \%, \mathrm{P}<0.05)$, and its ratio of N-6/N-3 was also better compared to Tunliu (5.4:1 $<5.9: 1)$. Air temperature has a positive effect on PUFA amount (Li et al., 2007). Annual mean temperature of Yicheng $\left(11.0^{\circ} \mathrm{C}\right)$ was higher than that of Tunliu $\left(9.3{ }^{\circ} \mathrm{C}\right)$. However, there was no difference in PUFA/SFA. This indicated that the unsaturated conversion of the two fatty acids of same carbon chain length are confined to definite unsaturated acids rather than saturate acids, despite of the difference of annual mean temperature in two production areas. 
Table 4. Fat nutrition characteristic of 6 walnut varieties yielded from Yicheng County

\begin{tabular}{|c|c|c|c|c|c|c|}
\hline $\begin{array}{l}\text { Walnut } \\
\text { Varieties }\end{array}$ & $\Sigma \mathrm{SFA} / \%$ & $\Sigma \mathrm{UFA} / \%$ & $\Sigma$ MUFA/\% & $\Sigma$ PUFA/\% & N-6/N-3 & PUFA/SFA \\
\hline Liaoning No.1 & 7.9 & 92.1 & 20.7 & 71.5 & 4.5 & 9.1 \\
\hline Luguang & 8.4 & 91.6 & 16.0 & 75.6 & 5.1 & 9.0 \\
\hline Lipin No.2 & 8.2 & 91.8 & 15.2 & 76.6 & 6.1 & 9.3 \\
\hline Beijing861 & 8.2 & 91.8 & 12.4 & 79.4 & 6.3 & 9.7 \\
\hline Zhonglin No.1 & 8.9 & 91.1 & 14.2 & 76.9 & 5.9 & 8.6 \\
\hline Zhonglin No.3 & 7.7 & 92.3 & 11.4 & 77.9 & 4.4 & 10.1 \\
\hline Average & 8.2 & 91.8 & 15.0 & 76.3 & 5.4 & 9.3 \\
\hline
\end{tabular}

$\Sigma$ SFA, $\Sigma$ UFA, $\Sigma$ MUFA and $\Sigma$ PUFA are abbreviated for the total amount of SFA, UFA, MUFA, and PUFA, respectively.

Table 5. Fat nutrition characteristic of 6 walnut varieties yielded from Tunliu County

\begin{tabular}{lllllll}
\hline Walnut & $\Sigma \mathrm{SFA} / \%$ & $\Sigma \mathrm{UFA} / \%$ & $\Sigma \mathrm{MUFA} / \%$ & $\Sigma$ PUFA/\% & N-6/N-3 & PUFA/SFA \\
Varieties & & & & & & \\
\hline Liaoning No.1 & 8.6 & 91.4 & 13.3 & 78 & 5.8 & 9.1 \\
Luguang & 7.5 & 92.5 & 19.5 & 72.6 & 4.9 & 9.7 \\
Lipin No.2 & 6.9 & 93.1 & 31.4 & 61.7 & 7.6 & 8.9 \\
Beijing861 & 5.6 & 94.4 & 22.4 & 72 & 6.0 & 12.9 \\
Zhonglin No.1 & 8.5 & 91.5 & 33.1 & 58.6 & 4.6 & 6.9 \\
Zhonglin No.3 & 8.2 & 91.8 & 23.3 & 68.5 & 6.3 & 8.4 \\
Average & 7.6 & 92.5 & 23.8 & 68.6 & 5.9 & 9.3 \\
\hline
\end{tabular}

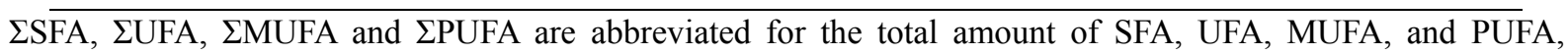
respectively.

There was a significant difference of $\alpha$-linolenic acid content (ALA) between Yicheng and Tunliu. The content of ALA of every variety from Yicheng was higher than that of Tunliu correspondingly (Figure 3). And then the average of $\alpha$-Linolenic acid was also more than that of Tunliu $(12.1 \%>10.2 \%$, average value). Annual mean temperature can affect the synthesis of ALA. With the annual mean temperature the content of ALA increases (Li et al., 2007). In our study, higher annual mean temperature of Yicheng $\left(11.0^{\circ} \mathrm{C}\right)$ had an increased amount of ALA compared to Tunliu $\left(9.3^{\circ} \mathrm{C}\right)$. This result can be explained for the differences of annual mean temperature in production areas. Higher annual mean temperature was always accompanied with longer frost-free period and illumination time, and these climate conditions can be also helpful to ALA biosynthesis. 


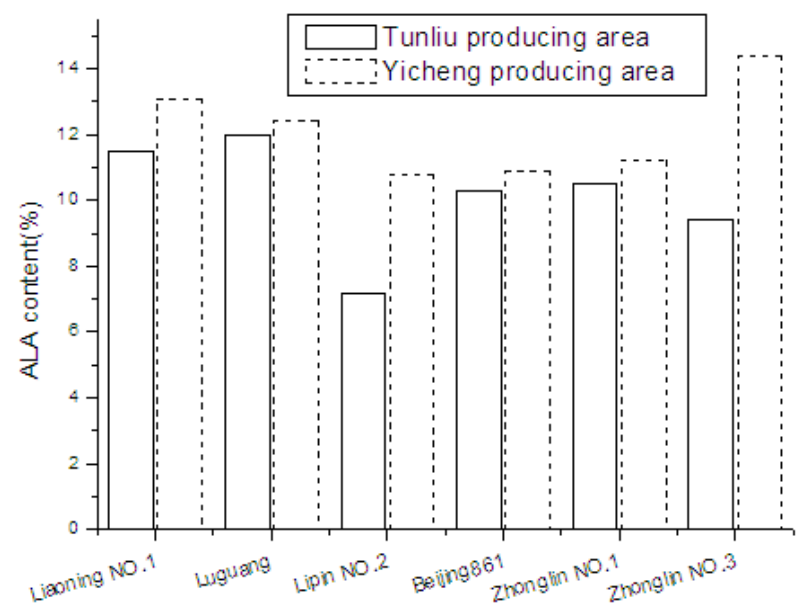

Figure 3. ALA content of walnut between Tunliu and Yicheng

ALA is the precursor of synthesize EPA (eicosapentaenoic acid) and DHA (Docosahexaenoic acid), and have also physiologically active like decreasing blood lipid, decreasing blood pressure, antithrombosis and preventing and curing athrosclerosis, etc. For the appropriate ratio of the N-6 to N-3 fatty acids (Simopoulos, 2002) also needs an important increase in ALA concentration. So it is strongly advised that the higher annual mean temperature should be considered to produce the ALA-rich walnut.

\section{Conclusion}

The content of oil of the most varieties from Tunliu with higher altitude was more than that of Yicheng of lower altitude, but the difference was insignificant.

The content of oleic acid and linoleic acid showed a significant difference between Tunliu and Yicheng. The differences of oleic and linoleic acid from two production areas can be considered as one index of fatty acid to compare. There is a negative relationship between the contents of oleic and linoleic acid despite of different production areas of walnut.

Annual mean temperature from different production areas has an obvious influence on $\alpha$-linolenic acid (ALA) content of walnut. The content of ALA of Yicheng with higher annual mean temperature is higher than that of Tunliu with lower annual mean temperature.

Higher altitude and lower annual mean temperature can help to produce oleic-rich walnut while lower altitude and higher annual mean temperature is helpful for the higher content of ALA in walnut kernel.

\section{Acknowledgments}

Thanks to Key Scientific and Technological Projects of Shanxi (20110311011-3) for financial assistance.

\section{References}

Cao, G. C. (1994). Wheat quality and ecology (p. 11-17). Beijing: Press of university of science and technology of China.

Chang, Y. M. (2011). Production status and development prospect of walnut in Shanxi province. Shanxi Fruits, 5, $39-41$.

Chen, J. Q., Zhang, Y., Gao, T. Y., Liu, F. Y., \& Tian, J. (2007). Selection of high-oil walnut cultivars. Northern Horticulture, 8, 27-29.

Li, G. H., Yang, D. S., \& Hu, T. G. (2007). Changes in fatty acid content of walnut in different production areas of Sichuan province. Scientia Silvae Sinicae, 43(5), 36-41.

Li, M., Liu, Y., Sun, C., Meng, Y. N., Yang, K. Q., Hou, L. Q., \& Wang, J. Y. (2009). Research advance about nutrients and medicinal value of walnut. Journal of the Chinese Cereals and Oils Ass Ciation, 24(6), 166-169.

Li, Z. J., Hua, J. Q., \& Zeng, Y. R. (2010a). Oil content of Camellia oleifera fruit trees. Journal of Zhejiang Forest Colleage, 27(6), 935-940. 
Li, Z. J., Hua, J. Q., \& Zeng, Y. R. (2010b). Effects of the climate during flowering period on post-flowering fruit setting in Camellia oleifera. Journal of Zhejiang Forest Colleage, 27(3), 323-328. http://dx.doi.org/10.1007/s11676-010-0078-z

Pyorala, K. (1987). Dietary cholesterol in relation to plasma cholesterol and coronary heart disease. Am. J. Clin. Nutr., 45, 1176-1184.

Simopoulos, A. P. (2002). The importance of the ratio of omega-6/omega-3 essential fatty acid. Biomed. Pharmacother, 56(8), 365-379. http://dx.doi.org/10.1016/S0753-3322(02)00253-6

Wang, X. N., Chen, Y. Z., Wu, L. Q., Liu, R. K., Yang, X. H., Wang, R., \& Yu, K. W. (2008). Oil content and fatty acid composition cameillia oleifera seed. Journal of Central South University Forestry \& Technology, 28(3), 12-17.

Wang, X. Y., Zhang, Z. H., Li, Y. Q., Zhao, H. R., \& Zhao, Y. P. (2004). Analysis of fatty acids composition and content in walnut varieties. Acta Nutrimenta Sinica, 26(6), 24-27.

Wu, K. Z., Xiao, Q. W., Tang, L. G., Pang, Y. C.,Wei, L., \& Zhang, L. (2007). Differences analysis on the contents of crude fat and amino acids in kernel of walnut. Nonwood Forest Research, 25(2), 15-18.

Xu, Y., Li, B. G., Wang, S., \& Zhong, Q. P. (2009). Correlation research situation of cultivation conditions and Camellia oleosa seed qualities. Nonwood Forest Research, 27(4), 108-113.

Zhang, Q., Cheng, B., Zhao, R. F., \& Zhang, Y. G. (2011). Analysis on the content of fatty acids and amino acids in Kernel of walnut varieties. J. Shanxi agric. Sci., 39(11), 1165-1169. http//dx.doi.org/10.39696/j.issn.1002-2481.2011.11.09

Zhang, Y., Lu, B., Feng, Q., Mao, Y. L., Bai, Y. S., \& Dong, J. (2011). Variation of fruit characters of walnut under different elevations. Journal of Northwest Forestry University, 26(4), 108-111.

\section{Copyrights}

Copyright for this article is retained by the author(s), with first publication rights granted to the journal.

This is an open-access article distributed under the terms and conditions of the Creative Commons Attribution license (http://creativecommons.org/licenses/by/3.0/). 